\title{
Creencias sobre series de ficción televisiva: el caso de Velvet ${ }^{1}$
}

\section{Beliefs about fiction television series: the case of Velvet}

\author{
Cristina Etayo Pérez. Universidad de Navarra
}

Recibido: 3-XI-2014 - Aceptado: 21-II-2015

Resumen:

Las series de televisión son un género de ficción muy atractivo tanto para los espectadores como para las cadenas que las emiten. Dados sus altos costes de producción, deben atraer al público desde el primer momento. Hay estudios sobre los factores que determinan el éxito de una película de cine pero se ha realizado escasa investigación sobre estos factores en series de televisión. En este trabajo se analizan las creencias de los espectadores sobre un conjunto de factores objetivos de la serie de televisión Velvet, emitida por Antena 3. Dado que estas creencias determinarán la posterior actitud hacia la serie, se profundiza en una serie de factores (sociodemográficas y de preferencias o gustos personales) para determinar si las diferencias en la valoración de la serie se ven influidas por estas variables (sexo, edad, consumo de televisión y preferencia por géneros). Los resultados indican que existen diferencias en las creencias que los espectadores tienen sobre Velvet que están influidas por los factores propuestos.

Palabras clave:

Televisión, ficción, series, creencias, Velvet.

Abstract:

Television series are an attractive genre of fiction programming not only for viewers but also for the channels that broadcast them. Given that production costs are high, such series need to draw high audience ratings from the start. Significant research has been carried out on the factors that condition the success of films released in movie theaters, but very little study has addressed the issues in relation to television series. The purpose of this paper is to explore viewer impressions of a range of objective factors relating to the series "Velvet", broadcast by Antena 3. Since such impressions may shape overall viewer attitude to the series, an in-depth analysis of a set of factors (sociodemographic factors, as well as matters of personal taste or interest) has been carried out to see whether different assessments of the series are influenced by such variables (sex, age, television consumption habits and preferences for different genres). The results suggest that viewer impressions of Velvet are affected by the factors cited above.

Keywords:

Television, fiction, series, beliefs, Velvet.

1 Este artículo es resultado del proyecto de investigación titulado "Nuevos hábitos de consumo digital en Europa: Impacto de la digitalización en la dieta de los ciudadanos y en la industria”. Referencia: CSO2010-20122. El proyecto está financiado por el Ministerio de Economía y Competitividad. 


\section{Introducción}

La ficción televisiva constituye un género de gran importancia en el conjunto de la programación de las cadenas. Los diferentes canales de televisión incorporan este género a sus parrillas de programación con la intención de atraer audiencia. En España, las seis principales cadenas generalistas dedican a la ficción desde un mínimo del 9,9\% del tiempo de emisión a un máximo del 30,7\%. Así, la cadena que más tiempo de su programación dedica a contenidos de ficción es Cuatro (30,7\%), seguida de Antena 3 (28.2\% del tiempo de emisión), Lal (19,0\%), La Sexta (14,7\%), y La2 y Tele 5 (ambas con un 9,9\%). (Kantar Media. Anuario Audiencias TV, 2013).

No obstante, en todas las cadenas, la aportación que estos contenidos suponen para la audiencia total de la cadena supera el porcentaje de tiempo de emisión, lo que permite afirmar que son contenidos que gustan a los televidentes y que mejoran las audiencias de las cadenas.

Uno de los géneros de ficción que ha experimentado un mayor incremento en su presencia en la programación es el de las series de ficción. A lo largo de los años se ha producido una mayor atracción de la audiencia por este tipo de contenidos (García de Castro, 2002). Sin embargo, se constata que existe un elevado porcentaje de fracasos entre los nuevos proyectos de series estrenadas, especialmente en lo referente a series españolas (García de Castro, 2007). Dado que el coste de producción de las series suele ser elevado, es importante analizar cuáles son los factores que influyen en la percepción que los espectadores tienen de ella, de forma que aumenten sus posibilidades de ser aceptada por el público. El conocimiento de cuáles son estos factores, por parte de los creadores y productores de las series de ficción, puede llevar a una mejor adaptación de las series a los gustos y preferencias del público objetivo.

Los elementos que influyen en la percepción de los productos audiovisuales por los telespectadores han sido analizados en la literatura, especialmente en lo que se refiere al cine. El análisis se ha centrado sobre todo en los efectos emocionales de la serie, es decir, en las actitudes, sentimientos y emociones que generan en la audiencia. En la literatura existen estudios de este tipo, aplicados al caso del cine (Igartua y Páez, 1997).

Así, el disfrute y entretenimiento durante el visionado, o la mejora del estado de ánimo después de ver la serie o la película son aspectos clave en este proceso, a pesar de que habitualmente se produce la denominada paradoja del drama (Oliver, 1989; Packer, 1989), que explica el hecho de que las personas disfrutan los dramas aun cuando lo pasen mal y su estado de ánimo se torne negativo tras su visionado (Oliver, 2003). Se han realizado estudios que ponen de manifiesto la relación positiva existente entre la tristeza provocada por el visionado del drama y el grado de disfrute experimentado (De Wied, Zillmann y Ordman, 1994; Igartua y Páez,1997). Otro aspecto que influye en el entretenimiento que proporciona un producto es la identificación con los personajes (Igartua y Paéz, 1998), esto es, el grado de empatía que se alcanza con ellos (Igartua y Múñiz, 2008; Cohen, 2001). Es importante también la resonancia personal (Vorderer, Klimmt y Ritterfeld, 
2004) los recuerdos de la propia vida que aparecen tras el visionado de la serie, la denominada memoria emocional (Oatley, 1999). También se ha analizado la importancia de la cercanía cultural, la consideración de que las situaciones que se presentan en la serie o película son próximas a la propia realidad del espectador (Larsen y Laszlo, 1990).

Aparte de todas estas variables emocionales referidas a cómo se siente el telespectador, en la evaluación de una serie también es importante conocer cuáles son las creencias de los espectadores hacia ella, es decir, cuál es su opinión sobre ella. Estas creencias no se limitan a una opinión global, sino que también pueden referirse a aspectos más concretos de la serie, como por ejemplo, los actores, los personajes, la ambientación o el vestuario. En definitiva las creencias se refieren a la valoración que realizan los individuos de unos aspectos objetivos, frente a las actitudes que hacen referencia a los sentimientos personales y por tanto, de naturaleza completamente subjetiva. Las actitudes se refieren a la evaluación favorable o desfavorable de un objeto, mientras que las creencias representan la información que una persona tiene sobre un objeto, es decir, las creencias representan juicios subjetivos, a pesar de que la información que una persona tenga sea objetiva (Petty y Cacioppo, 1996).

Las creencias en nuestro trabajo se refieren a juicios subjetivos que la persona hace sobre los atributos de la serie mientras que las actitudes hacen referencia a evaluaciones positivas o negativas sobre la misma. Así, como muestran Fishbein y Ajzen (1975), la estructura de las creencias proporciona la base cognitiva de las actitudes, es decir, la actitud hacia la serie se basa en las creencias que se tengan sobre ella.

En este trabajo se ofrece un modelo integrado de las creencias de los telespectadores respecto a una serie, Velvet (emitida por Antena 3), identificando aspectos objetivos que los telespectadores pueden valorar de diferentes maneras. Concretamente, los elementos clave que se han analizado para Velvet son: diálogos, tramas, actores, personajes, ambientación y vestuario, riqueza de recursos, contenidos molestos, originalidad, variedad y calidad. Se estudia cómo se evalúan cada uno de estos elementos en esta serie concreta. Además, se analiza si esta valoración se ve afectada por la variables sociodemográficas (sexo y edad), por hábitos de consumo de televisión y por preferencia por géneros. Se trata de poner de manifiesto si en la evaluación final de cada uno de estos elementos influyen las características sociodemográficas y de preferencias o gustos personales.

\section{Metodología}

La serie elegida para realizar este análisis es Velvet, cuya primera temporada comenzó a emitirse el 17 de febrero de este mismo año, 2014. Los capítulos de la serie se emitieron de ese día al 26 de mayo de este año. La audiencia media de la serie fue de 4.262.000 espectadores con un 21,8 de share. La serie cuenta con un alto presupuesto (Campos, 2013).

Se eligió esta serie porque era una de las que estaban emitiéndose en el momento de realizar el trabajo, lo que facilitaba el recuerdo de los espectadores y una evaluación de los elementos que se le planteaban más acorde con la realidad. La téc- 
nica utilizada para la obtención de los datos fue la encuesta, que se administró a 385 personas, con las cuotas de sexo y edad que se indican a continuación. La encuesta se realizó de forma personal.

Se realizó la encuesta a 375 personas (178 hombres y 197 mujeres). La distribución por edades es la siguiente. Hay 63 personas que tenían entre 14 y 24 años ( 32 hombres y 31 mujeres), 138 tenían de 25 a 44 años (67 hombres y 71 mujeres), 104 personas de edades entre 45 y 65 años ( 47 hombre y 57 mujeres) y 70 personas mayores de 65 años (32 hombre y 38 mujeres. Para la realización de la encuesta se exigía al encuestado que hubiera visto al menos uno de los capítulos de la serie. Para ello, la primera pregunta que se formulaba era sobre conocimiento del contenido. ¿Cómo considera que es su conocimiento de la serie? Se ofrecían las siguientes respuestas. 1. No la conozco en absoluto, 2. He oído hablar de ella pero no he visto nada sobre ella. 3. He visto solo publicidad sobre la misma. 4. He visto al menos un capítulo. 5. He visto algunos capítulos. 6. He visto todos los capítulos.

Solamente se procedía a la realización de la encuesta si las respuestas a la primera pregunta eran la 4, 5 o 6. Si esto no sucedía, se reemplazaba al encuestado por otro que cumpliera el requisito. La encuesta se realizó durante el mes de abril de 2014.

A partir de este momento se pedía a los espectadores que evaluaran diversos aspectos de la serie, como diálogos, tramas, actores, personajes, ambientación y vestuario, recursos con los que cuenta la serie, contenidos molestos, originalidad, variedad y calidad. Una vez obtenidos los datos se realizó un análisis de varianza para ver si existen diferencias en la consideración que de los mismos tienen personas de distinto sexos y edad. Se trataba de ver si la valoración de estos aspectos varía en función de si ese es hombre o mujer o de si se es más joven o más mayor. También se realizó el estudio discriminando entre personas que ven mucho la televisión tanto a diario como en fin de semana y personas que la ven poco, mediante un análisis de correlaciones. Por último se analizaron estos factores para ver si existen diferencias en cuanto a la preferencia por unos y otros géneros de televisión utilizando de nuevo la correlación.

\section{Las creencias de los espectadores sobre Velvet}

\subsection{Descripción general}

En este apartado se estudian genéricamente las creencias de los telespectadores sobre Velvet. A partir de la información incluida en el Cuadro 1 se examina la consideración que los telespectadores realizan de los diferentes aspectos que constituyen sus creencias en relación con la serie. Ello nos va a permitir conocer la valoración que hacen de los diferentes elementos, así como evaluar cuáles de ellos cuentan con una mayor aceptación entre la audiencia.

Diálogos. En primer lugar se analizan las creencias sobre los diálogos que mantienen los personajes de Velvet. Para ello se han formulado tres preguntas que tratan de recoger en una escala de cero a diez la percepción de los espectadores sobre 
los siguientes aspectos concretos: si las conversaciones entre los protagonistas son muy interesantes, si los diálogos son muy inteligentes y, finalmente, si los diálogos están muy trabajados.

Como se puede apreciar, las medias muestrales para estos tres ítems son muy similares (al igual que sus desviaciones típicas), encontrándose el menor valor para "los diálogos son muy inteligentes" $(4,97)$ y siendo idénticos los promedios para los dos ítems restantes. Si calculamos el promedio de las puntuaciones medias para las tres preguntas, es igual a 5,2. Ello indica que la calificación que los telespectadores otorgan a los diálogos de Velvet se sitúa justamente en el aprobado, por lo que no se trata de una dimensión en la que la serie parezca destacar especialmente para la audiencia.

Tramas. Para la valoración de esta dimensión se establecen siete ítems distintos, relativos a diversos aspectos relacionados con las tramas que acontecen en la serie. El primero de ellos hace referencia al grado de atención necesario para entender la serie. La puntuación media para este ítem es de 4,22, lo que indica que Velvet no es percibida como una serie especialmente complicada de entender. A través del segundo ítem se evalúa si los episodios de la serie resultan difíciles de seguir, siendo la puntuación sensiblemente baja: un 2,93. Esto apunta a que los espectadores no encuentran apenas dificultad en seguir cada episodio. Un resultado similar se obtiene para el tercer ítem, que se refiere el nivel de complicación de las historias que se relatan en la serie. El 2,82 que se obtiene de media permite concluir que la audiencia no encuentra problemas especialmente importantes para seguir la serie.

El cuarto ítem analizado, "dentro de un mismo capítulo pasan cosas diferentes", por el contrario, alcanza un valor medio sustancialmente más elevado que los ítems anteriores $(5,28)$, lo que indica que los telespectadores creen que la serie tiene un ritmo medio y que cada capítulo presenta una variedad de contenidos intermedia. Este resultado se ve refrendado por el obtenido para la siguiente pregunta ("hay muchas tramas diferentes en cada capítulo"), que alcanza también una puntuación de 4,83.

Para el ítem "La trama es tan buena que engancha rápidamente" se obtiene una puntuación de 5,33, lo que nos permite afirmar que la historia tiene una capacidad intermedia para conectar con el público y hacerle ver la serie semana tras semana. La puntuación más alta obtenida para los aspectos referidos a la trama se logra para el ítem "las historias están bien construidas", que alcanza un valor medio de 6,41 para la muestra. De este modo, los espectadores valoran la calidad en la construcción de las distintas historias que plantea la serie y las perciben como continuas y, por tanto, creíbles.

En consecuencia, en lo que se refiere a la trama de Velvet, el análisis de los datos parece indicar que, si bien las historias son coherentes y resultan bastante fáciles de comprender para la audiencia, introducen ciertos elementos de variedad que hacen necesario prestar cierto nivel de atención en cada emisión para poder estar al tanto del desarrollo de la serie.

Actores. Para valorar el elenco de actores que participan en la serie, se utiliza la información procedente de tres preguntas. La primera de ellas indaga en las creencias del público sobre si los actores son buenos, la segunda sobre si interpretan 
bien su papel en la serie y por último, sobre si se ajustan bien a sus personajes. Los promedios de las respuestas obtenidos en estos tres ítems oscilan entre 6,09, para la primera pregunta, es decir sobre si los actores son buenos, y un 6,57 en su grado de ajuste a los personajes. Esto indica que los espectadores creen que los actores están muy bien elegidos para el papel que representan y que interpretan bien su papel en ligera mayor medida que consideran que se trata de un buen reparto. La media de los tres ítems es de 6,3, por lo que puede considerarse un aspecto que está positivamente valorado por el público, sin llegar a alcanzar el notable pero por encima de los diálogos y las tramas.

Personajes.Para valorar las creencias respecto a los personajes de la serie se plantean nuevamente tres preguntas. La primera de ellas trata de desentrañar si los personajes resultan creíbles o no. La puntuación media de las respuestas es de 6,14. La segunda pregunta, que examina si los personajes son percibidos como interesantes, ofrece una puntuación más baja, de 5,89. El tercer ítem analizado aborda si los personajes están bien definidos, alcanzando una puntuación promedio de 6,42. Como puede comprobarse, el aspecto peor valorado de los tres es el interés de los personajes, y el mejor su definición. La media de todos los ítems es de 6,15 lo que nos indica que se valora algo mejor a los actores de la serie que a los personajes que representan.

Ambientación y vestuario. La ambientación y el vestuario presentados en Velvet se valoran a través de dos ítems, uno para cada uno de los dos aspectos. La primera pregunta, sobre si la ambientación está muy bien conseguida, alcanza una puntuación media en las respuestas de 7,29. La segunda pregunta, sobre si el vestuario es muy realista, llega al 7,74. La media de ambos ítems, 7,5, indica que la audiencia valora muy positivamente estos dos aspectos de la serie. Se trata claramente del aspecto, de todos los aquí analizados, mejor valorado por parte de los espectadores, que consideran que el vestuario la ambientación de la época concreta en que la serie se desarrolla están conseguidos en la serie de forma notable.

Riqueza de recursos.Para la evaluación de los medios disponibles en la producción de la serie se emplean dos ítems. El primero de ellos consiste en la afirmación "se nota que la serie ha contado con una alto presupuesto". La puntuación media obtenida para esta pregunta ha sido de 6,95, es decir, los espectadores consideran que la serie se ha rodado con un presupuesto notable. La segunda pregunta hace referencia a que "en el rodaje no se ha escatimado en medios técnicos". La puntación alcanzada en este caso es de 6,47. Ello confirma que los espectadores perciben que se encuentran ante una serie que ha contado para su producción con un notable conjunto de recursos.

Contenidos molestos. Una dimensión importante en las creencias sobre una serie es si contiene contenidos o escenas desagradables para el espectador, bien sea por cuestiones de moralidad o de carácter estético. Para determinar este punto, se estudian tres cuestiones distintas. La primera de ellas hacer referencia a si el telespectador cree que en la serie ocurren cosas desagradables, que puedan disgustarle. Como puede verse en el Cuadro 1, la puntuación media alcanzada es de 3,19, es decir, no parece que Velvet sea una serie que contenga elementos que resultan desagradables para la audiencia. La segunda valoración es respecto a la presencia de contenidos violentos. En este caso la puntuación es extremadamente baja

94 | n²0, pp. 89-118| doxa.comunicación 
$(1,96)$, por lo que puede afirmarse que no nos encontramos en absoluto ante una serie que sea percibida como violenta en sus contenidos por el público. La tercera y última pregunta hace referencia la inmoralidad de los contenidos. Para este ítem la puntuación es de 3,26, lo que nos indica que los espectadores perciben que la serie apenas incluye contenidos inmorales. Aunque no es una puntuación muy alta en términos absolutos, los valores obtenidos ponen de manifiesto que Velvet es percibida significativamente más como inmoral que como violenta.

Originalidad. Para la evaluación de Velvet no solo en sí misma, sino en comparación con otras series de ficción se examina la dimensión de originalidad. Para determinar la valoración de los espectadores respecto a esta cuestión se preguntaron dos cuestiones. La primera, si se considera que la serie es muy diferente a otras y, la segunda, si la serie es original. En la primera cuestión analizada la puntuación media obtenida es 4,29, es decir, no se llega al aprobado, por lo que no parece que el público perciba la serie como muy diferente a otras que se emiten o se han emitido. A conclusiones similares se llegan tras el análisis de la puntuación obtenida para la afirmación "es una serie muy original”. De nuevo, el valor alcanzado no llega a 5 puntos (es del 4,48), por lo que puede decirse que la originalidad sea una característica por la que la serie destaque de acuerdo con el criterio del público.

Variedad. Para el análisis de la variedad que en la serie perciben los telespectadores se analizan las respuestas a tres cuestiones. La primera de ellas indaga sobre la repetitividad de la serie; en la segunda se analiza si cada nuevo capítulo sorprende a la audiencia y en la tercera se examina si el espectador estima que nunca se sabe por dónde va a ir la trama. Para la primera afirmación ("la serie no es nada repetitiva"), la puntuación media en la muestra es de 4,34. Esto nos indica que los espectadores creen que hay cierta dosis de repetición en el transcurso de la serie. Para la segunda cuestión (si cada capítulo es novedoso y sorprende), se alcanza una puntuación media muy similar (4,39). Respecto a la tercera cuestión ("nunca sabes por donde va a ir la trama"), el valor medio de las respuestas obtenidas a esta pregunta es de 4,20. En líneas generales, aunque con matices, estos resultados apuntan a que los telespectadores creen que Velvet es una serie donde hay un importante grado de repetitividad y previsibilidad.

Calidad. La última dimensión que abordamos es la calidad percibida de la serie, que puede entenderse como el resumen y la consecuencia integrada del resto de creencias consideradas previamente. Si bien la calidad puede considerarse desde otras perspectivas más objetivas y técnicas, en la línea de lo que son los objetivos de la presente investigación, la calidad es evaluada a continuación de acuerdo con la percepción que se han formado los espectadores tras el visionado de los capítulos de la serie.

Para la medición de la calidad se emplean tres ítems.La primera pregunta cuestiona la factura técnica de la serie. La respuesta media al ítem "Está muy bien hecha" alcanza una puntuación de 6,55, lo que nos indica que los espectadores valoran favorablemente este aspecto. Para la segunda cuestión ("es una serie de calidad"), la puntuación baja a 6,03. Aunque este es inferior al anterior, no obstante indica que los espectadores la consideran una buena serie en términos de su calidad. 
La última de las cuestiones, planteada en términos más exigentes ("es una serie excelente") da lugar a una puntuación de 5,14. Esto nos indica que si bien los espectadores consideran que la serie es de calidad y sobre todo, que está muy bien hecha, se retraen a la hora de considerarla como una serie que pueda pertenecer a la exclusiva categoría de las excelentes.

Cuadro 1. Las creencias de los telespectadores sobre Velvet: media y desviación típica

\begin{tabular}{|c|c|c|}
\hline DIÁLOGOS & Media & Desv. típica \\
\hline Las conversaciones de los protagonistas son muy interesantes & 5.31 & 2.399 \\
\hline Los diálogos son muy inteligentes & 4.97 & 2.273 \\
\hline Los diálogos están muy trabajados & 5.31 & 2.303 \\
\hline \multicolumn{3}{|l|}{ TRAMAS } \\
\hline Hay que estar muy atento para enterarse bien & 4.22 & 2.647 \\
\hline Los episodios son difíciles de seguir & 2.93 & 2.444 \\
\hline Las historias son complicadas de entender & 2.82 & 2.421 \\
\hline Dentro de un mismo capítulo pasan cosas diferentes & 5.28 & 2.347 \\
\hline Hay muchas tramas diferentes en cada capítulo & 4.83 & 2.281 \\
\hline Las historias están muy bien construidas & 6.41 & 2.581 \\
\hline La trama es tan buena que engancha rápidamente & 5.33 & 2.677 \\
\hline \multicolumn{3}{|l|}{ ACTORES } \\
\hline Los actores son muy buenos & 6.09 & 2.384 \\
\hline Los actores interpretan bien su papel & 6.35 & 2.341 \\
\hline Los actores se ajustan muy bien a sus personajes & 6.57 & 2.183 \\
\hline \multicolumn{3}{|l|}{ PERSONAJES } \\
\hline Los personajes me resultan muy creíbles & 6.14 & 2.445 \\
\hline Los personajes son muy interesantes & 5.89 & 2.582 \\
\hline Los personajes están muy bien definidos & 6.42 & 2.247 \\
\hline \multicolumn{3}{|l|}{ AMBIENTACIÓN Y VESTUARIO } \\
\hline La ambientación está muy bien conseguida & 7.29 & 2.196 \\
\hline El vestuario es muy realista & 7.74 & 1.968 \\
\hline \multicolumn{3}{|l|}{ RIQUEZA DE RECURSOS } \\
\hline Se nota que la serie ha contado con un alto presupuesto & 6.95 & 2.202 \\
\hline En el rodaje no se ha escatimado en medios técnicos & 6.47 & 2.205 \\
\hline
\end{tabular}

96 | n²0, pp. 89-118 | doxa.comunicación 


\begin{tabular}{|c|c|c|}
\hline CONTENIDOS MOLESTOS & Media & Desv. típica \\
\hline En la serie pasan cosas desagradables & 3.19 & 2.731 \\
\hline Tiene contenidos violentos & 1.96 & 2.270 \\
\hline Tiene contenidos inmorales & 3.26 & 2.781 \\
\hline \multicolumn{3}{|l|}{ ORIGINALIDAD } \\
\hline Es muy diferente a otras series & 4.29 & 2.592 \\
\hline Es una serie muy original & 4.48 & 2.574 \\
\hline \multicolumn{3}{|l|}{ VARIEDAD } \\
\hline La serie no es nada repetitiva & 4.34 & 2.552 \\
\hline Cada nuevo capítulo te sorprende & 4.39 & 2.596 \\
\hline Nunca sabes por dónde va a ir la trama & 4.20 & 2.471 \\
\hline \multicolumn{3}{|l|}{ CALIDAD } \\
\hline Está muy bien hecha & 6.55 & 2.207 \\
\hline Es una serie de calidad & 6.03 & 2.354 \\
\hline Es una serie excelente & 5.14 & 2.652 \\
\hline
\end{tabular}

Fuente: Elaboración propia

A modo de resumen, el Gráfico 1 muestra los valores medios de los ítems utilizados para medir cada una de las dimensiones de Velvet consideradas en este artículo. Como puede observarse, la dimensión más valorada es la ambientación y vestuario, seguida de la riqueza de recursos en su producción. Esto significa que los espectadores son conscientes y valoran el presupuesto destinado a la producción de la serie. También están muy bien valorados los actores elegidos para la serie, así como los personajes que representan. Por su parte, los diálogos y tramas obtienen una valoración intermedia. Las dimensiones menos valoradas son la originalidad, lo que indica que Velvet no se percibe como una serie novedosa o innovadora, y la variedad, lo que significa que la serie puede llegar a ser repetitiva. Como aspecto positivo, destacar que los contenidos de la serie no resultan molestos para el espectador. En este caso, una puntuación baja implica una valoración positiva.

Por último, señalar que el valor obtenido para la calidad percibida de la serie refleja en gran medida la valoración proporcionada por los espectadores a las diferentes dimensiones estudiadas, de tal forma que se sitúa en una situación intermedia. Por un lado, desde el punto de vista positivo, se considera que es una serie muy bien hecha, resultado de la riqueza de recursos con los que cuenta y de la buena ambientación de la época en que se desarrolla además de un vestuario muy conseguido. Sin embargo, los aspectos más débiles de la serie, como son su poca originalidad y la falta de variedad, 
hacen que el nivel de calidad se perciba como inferior a la valoración obtenida por los aspectos más positivos de la serie. Está claro que una alta disponibilidad de recursos puede elevar la calidad de la serie, pero también que todas las dimensiones deben estar cuidadas para que la serie sea percibida como de alta calidad. Los datos indican que Velvet podría ser mejorada haciéndose más variada, y mejorando las tramas desarrolladas en la serie, con más originalidad y una mayor la calidad en los diálogos.

Gráfico 1. Creencias de los espectadores sobre diferentes aspectos de Velvet (valor medio en una escala de 0 a 10 de los ítems empleados para cada dimensión)

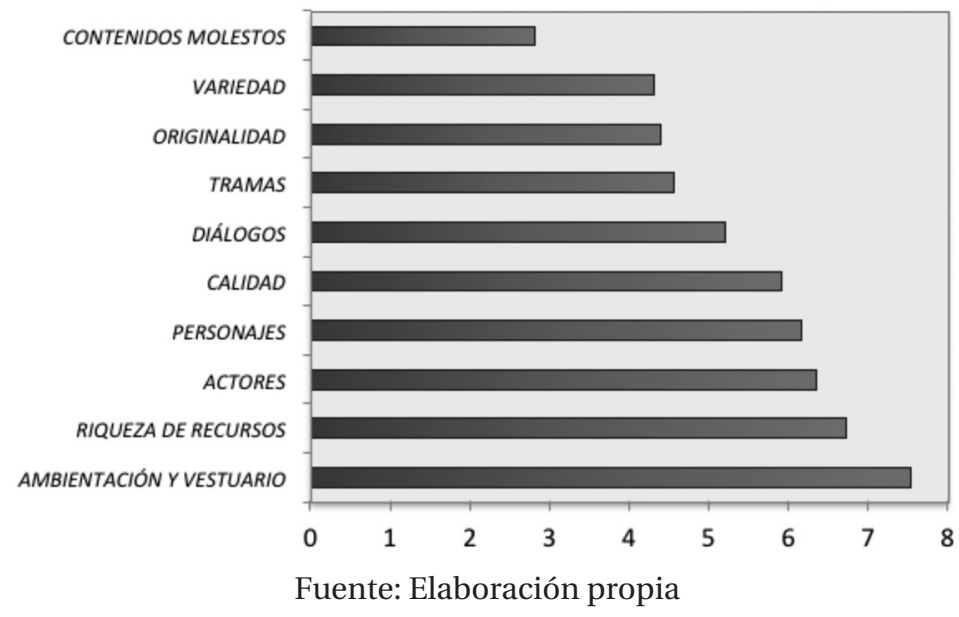

\subsection{La relación con el género del telespectador}

Una vez analizadas las creencias de los espectadores sobre Velvet, a continuación abordamos si existen diferencias en sus diferentes dimensiones entre hombres y mujeres. Se trata de examinar si los espectadores de los dos sexos comparten o no sus creencias respecto a la serie. Para ello se calculan las medias de las puntuaciones de cada uno de los ítems para los dos grupos (hombres y mujeres) y se contrasta a través del análisis de la varianza si existen diferencias entre ambas. El análisis de la varianza es la técnica habitualmente empleada para comprobar la existencia de variación entre varios grupos respecto de una variable cuantitativa. La hipótesis nula que se contrasta es que las valoraciones en ambos grupos (hombres y mujeres) son iguales. Valores altos del estadístico F de Fisher indicarían que esta hipótesis no se cumple, lo que llevaría a concluir que las diferencias entre hombres y mujeres son estadísticamente significativas. Para indicar si el valor de F implica diferencias estadísticamente significativas, utilizamos el símbolo asterisco, de tal manera que un asterisco indica una significación del 10\%, dos asteriscos una significación del 5\% y tres asteriscos una significación del 1\%. La información sobre estos análisis se encuentra en el Cuadro 2.

98 | n²0, pp. 89-118| doxa.comunicación 
Diálogos. Como puede observarse en el Cuadro 2, cuando se trata de valorar los diálogos que los personajes mantienen en la serie, se aprecian diferencias estadísticamente significativas entre hombres y mujeres. Las mujeres opinan en mayor medida que los hombres que las conversaciones en Velvet son muy interesantes ( $F=12.698, p<0.01)$ y que los diálogos son inteligentes $(\mathrm{F}=11.896, \mathrm{p}<0.01)$ y están muy trabajados $(\mathrm{F}=7.204, \mathrm{p}<0.01)$.

Tramas. En cuanto a la valoración de las tramas, parece existir algo más de acuerdo entre hombres y mujeres para algunas cuestiones. Concretamente, para los ítems "hay que estar atento para enterarse bien", "los episodios son difíciles de seguir", "dentro de un mismo capítulo pasan cosas diferentes" y "hay muchas tramas diferentes en cada capítulo" no se puede rechazar la hipótesis nula de que las creencias de hombres y mujeres al respecto son iguales. Sin embargo, en lo que concierne a complejidad percibida de las historias, a éstas les resultan más difíciles de entender a los hombres que a las mujeres, no aceptándose la hipótesis nula de igualdad de medias entre hombres y mujeres ( $\mathrm{F}=4.105, \mathrm{p}<0.05)$ También se aprecian diferencias estadísticamente significativas en otras dos de las cuestiones planteadas. Para la pregunta sobre si las historias están bien construidas, los hombres otorgan una puntuación media de 6,02, mientras que la otorgada por las mujeres toma un valor promedio de 6,77 ( $\mathrm{F}=8.116, \mathrm{p}<0.01)$. Lo mismo sucede para el ítem "la trama es tan buena que engancha rápidamente” ( $\mathrm{F}=7.118, \mathrm{p}<0.01)$. En este caso, la puntuación asignada por los hombres no llega al aprobado $(4,94)$, mientras que la proporcionada por los mujeres es de 5,67.

Actores. Las diferencias entre hombres y mujeres en las valoraciones del reparto son estadísticamente significativas para las tres preguntas que evalúan esta dimensión de la serie, no aceptándose la hipótesis nula de igualdad de creencias entre hombres y mujeres. Se observa con claridad cómo las mujeres consideran en mayor medida que los hombres que los actores de Velvet son buenos ( $\mathrm{F}=3.963$, $\mathrm{p}<0.05)$, que interpretan bien su papel $(\mathrm{F}=4.925, \mathrm{p}<0.05)$ y que se ajustan muy bien a sus personajes $(\mathrm{F}=5.144, \mathrm{p}<0.05)$.

Personajes. Los resultados son similares en relación con las creencias sobre los personajes de la serie. De nuevo la valoración de las mujeres es superior a la de los hombres para los tres ítems relacionados con esta cuestión, no aceptándose la hipótesis nula de igualdad de medias entre hombres y mujeres. A las mujeres los personajes de Velvet les resultan más creíbles que a los hombres ( $\mathrm{F}=3.512, \mathrm{p}<0.10)$, amén de más interesantes $(\mathrm{F}=8.276, \mathrm{p}<0.01)$. Asimismo, opinan que los personajes de la serie están mejor definidos ( $\mathrm{F}=6.539, \mathrm{p}<0.01)$. Como indican los valores del estadístico $\mathrm{F}$, las diferencias son estadísticamente más significativas para el interés de los personajes y su buena definición que para su credibilidad.

Ambientación y vestuario. Si se comparan las opiniones de hombres y mujeres sobre la ambientación y el vestuario de Velvet, aun siendo ambas muy positivas para ambos grupos, nuevamente detectamos que la valoración de las mujeres es significativamente mejor, rechazándose la hipótesis nula de igualdad de medias ( $\mathrm{F}=6.340$ y F=6.454, respectivamente; $\mathrm{p}<0.05$ en ambos casos) 
Riqueza de recursos. Los resultados difieren de los anteriores cuando se trata de opinar sobre la riqueza de recursos medios técnicos con los que cuenta la serie, que se estudia mediante los ítems "se nota que la serie ha contado con un alto presupuesto" y "en el rodaje no se ha escatimado en medios técnicos". En esta dimensión se observa que no hay diferencias estadísticamente significativas entre las opiniones de hombres y mujeres, es decir, no se puede rechazar la hipótesis de que ambos consideran en la mismal medida que los medios técnicos con los que cuenta la realización de la serie son amplios.

Contenidos molestos. En cuanto a si los contenidos de Velvet resultan molestos, encontramos que aunque se acepta la hipótesis nula de que las opiniones de hombres y mujeres sobre la evaluación moral de la serie y la existencia de contenidos desagradables son iguales, sí que existen diferencias significativas $(\mathrm{F}=4.483, \mathrm{p}<0.05)$ en las respuestas a la pregunta sobre la violencia de los contenidos. Para esta cuestión los hombres creen que hay una mayor presencia de contenidos violentos.

Originalidad. Respecto a la evaluación de la originalidad de la serie, no se observan diferencias estadísticamente significativas entre ambos sexos. Esta ausencia de diferencias sucede para los dos ítems utilizados en este sentido: "es muy diferente a otras series", y "es una serie muy original".

Variedad. En el análisis de las creencias respecto a la variedad de la serie, a partir del análisis de la varianza no se detectan diferencias estadísticamente significativas en los ítems "la serie no es nada repetitiva" y "nunca sabes por donde va a ir la trama”. Por el contrario, sí que se rechaza la hipótesis de medias iguales para hombres y mujeres ( $(\mathrm{F}=7.362, \mathrm{p}<0.01)$ en el ítem "cada nuevo capítulo te sorprende", ya que las mujeres consideran en mayor medida que los hombres que cada nuevo capítulo de Velvet aporta una dosis de novedad inesperada.

Calidad. En la evaluación de la última dimensión analizada, la calidad, vemos que existen diferencias muy significativas entre ambos sexos. Las mujeres consideran en mayor medida que los hombres a Velvet como una serie de calidad. Esto ocurre para los tres ítems considerados. La asociación estadística encontrada para la calidad es la mayor de entre todas las analizadas, como lo confirman los valores que toma la F para "está muy bien hecha" ( $\mathrm{F}=14.230, \mathrm{p}<0.01$ ), "es una serie de calidad" ( $\mathrm{F}=13.079, \mathrm{p}<0.01)$ y "es una serie excelente" ( $\mathrm{F}=10.072, \mathrm{p}<0.01)$. Este resultado parece la consecuencia lógica de todas las asociaciones anteriores encontradas entre el sexo y el resto de las creencias examinadas. 
Cuadro 2. Las creencias en función del sexo: resultados del análisis de la varianza

\begin{tabular}{|c|c|c|c|}
\hline DIÁLOGOS & Hombres & Mujeres & $\mathbf{F}$ \\
\hline Las conversaciones de los protagonistas son muy interesantes & 4.86 & 5.72 & $12.598^{* * *}$ \\
\hline Los diálogos son muy inteligentes & 4.55 & 5.34 & $11.896^{* * *}$ \\
\hline Los diálogos están muy trabajados & 4.98 & 5.61 & $7.204^{* * *}$ \\
\hline \multicolumn{4}{|l|}{ TRAMAS } \\
\hline Hay que estar muy atento para enterarse bien & 4.21 & 4.22 & 0.001 \\
\hline Los episodios son difíciles de seguir & 3.08 & 2.81 & 1.175 \\
\hline Las historias son complicadas de entender & 3.08 & 2.58 & $4.105^{* *}$ \\
\hline Dentro de un mismo capítulo pasan cosas diferentes & 5.19 & 5.37 & 0.553 \\
\hline Hay muchas tramas diferentes en cada capítulo & 4.87 & 4.79 & 1.135 \\
\hline Las historias están muy bien construidas & 6.02 & 6.77 & $8.116^{* * *}$ \\
\hline La trama es tan buena que engancha rápidamente & 4.94 & 5.67 & $7.118^{* * *}$ \\
\hline \multicolumn{4}{|l|}{ ACTORES } \\
\hline Los actores son muy buenos & 5.83 & 6.32 & $3.963^{* *}$ \\
\hline Los actores interpretan bien su papel & 6.07 & 6.60 & $4.925^{* *}$ \\
\hline Los actores se ajustan muy bien a sus personajes & 6.31 & 6.81 & $5.144^{* *}$ \\
\hline \multicolumn{4}{|l|}{ PERSONAJES } \\
\hline Los personajes me resultan muy creíbles & 5.89 & 6.36 & $3.512^{*}$ \\
\hline Los personajes son muy interesantes & 5.49 & 6.24 & $8.276^{* * *}$ \\
\hline Los personajes están muy bien definidos & 6.11 & 6.70 & $6.539 * * *$ \\
\hline \multicolumn{4}{|l|}{ AMBIENTACIÓNYVESTUARIO } \\
\hline La ambientación está muy bien conseguida & 6.99 & 7.55 & $6.340^{* *}$ \\
\hline El vestuario es muy realista & 7.47 & 7.99 & $6.454^{* *}$ \\
\hline \multicolumn{4}{|l|}{ RIQUEZA DE RECURSOS } \\
\hline Se nota que la serie ha contado con un alto presupuesto & 6.91 & 6.99 & 0.141 \\
\hline En el rodaje no se ha escatimado en medios técnicos & 6.42 & 6.50 & 0.118 \\
\hline \multicolumn{4}{|l|}{ CONTENIDOS MOLESTOS } \\
\hline En la serie pasan cosas desagradables & 3.22 & 3.15 & 0.059 \\
\hline
\end{tabular}




\begin{tabular}{|l|c|c|c|}
\hline \multicolumn{1}{|l|}{} & Hombres & Mujeres & \multicolumn{1}{|c|}{ F } \\
\hline Tiene contenidos violentos & 2.22 & 1.73 & $4.483^{* *}$ \\
\hline Tiene contenidos inmorales & 3.31 & 3.21 & 0.128 \\
\hline ORIGINALIDAD & 4.21 & 4.31 & 0.348 \\
\hline Es muy diferente a otras series & 4.43 & 4.52 & 0.101 \\
\hline Es una serie muy original & \multicolumn{4}{|l|}{} \\
\hline VARIEDAD & 4.11 & 4.54 & 2.638 \\
\hline La serie no es nada repetitiva & 4.01 & 4.73 & $7.362^{* * *}$ \\
\hline Cada nuevo capítulo te sorprende & 4.08 & 4.30 & 0.690 \\
\hline Nunca sabes por dónde va a ir la trama & & \multicolumn{1}{|l|}{} \\
\hline CALIDAD & 6.11 & 6.95 & $14.230^{* * *}$ \\
\hline Está muy bien hecha & 5.58 & 6.44 & $13.079^{* * *}$ \\
\hline Es una serie de calidad & 4.69 & 5.54 & $10.072^{* * *}$ \\
\hline Es una serie excelente
\end{tabular}

Fuente: Elaboración propia

${ }^{*} \mathrm{p}<0.10,{ }^{* *} \mathrm{p}<0.05,{ }^{* * *} \mathrm{p}<0.01$

\subsection{La relación con la edad del telespectador}

Seguidamente se examina si las creencias del telespectador acerca de Velvet están relacionadas con su edad. Para ello se han definido cuatro grupos de la audiencia en función de esta característica demográfica: entre 14 y 24 años, de 25 a 44 años, de 45 a 64 años y personas de 65 o más años. Al igual que en el subapartado anterior, se han calculado las medias de las puntuaciones para cada uno de los ítems para los cuatro grupos de edad y se estudia si las diferencias entre ellos son significativas a partir de los resultados del análisis de la varianza. El valor del estadístico F determina si la diferencia puede o no considerarse como significativa, haciendo que se acepte o se rechace la hipótesis nula de igualdad de medias entre los cuatro grupos de edad analizados. Esta información figura en el Cuadro 3.

Diálogos. En cuanto a los diálogos de la serie, se observa la existencia de diferencias estadísticamente significativas en su consideración por parte de los diferentes grupos de edad. Los valores del estadístico F son 2.681 ( $<<0.05)$ para "las conversaciones de los protagonistas son muy interesantes”, 2.713 ( $\mathrm{p}<0.05)$ para “los diálogos son muy inteligentes” y 3.657 ( $\mathrm{p}<0.05)$ para "los diálogos están muy trabajados". Las personas del tramo de edad superior creen en mayor medida que el resto de segmentos que tanto las conversaciones de los protagonistas son muy interesantes como que los diálogos son 
inteligentes y están muy trabajados. Sin embargo, no se detecta una asociación entre edad y creencias sobre los diálogos uniforme para los tres grupos de edad restantes. Así, mientras que los televidentes de entre 45 y 64 años tienen una mayor creencia que los de menos de 45 años de que las conversaciones entre los personajes son interesantes, ello no sucede para la percepción de que los diálogos son interesantes y están muy trabajados. En estos casos las personas de entre 25 y 44 años son quienes muestran una visión más positiva que las de entre 14 y 24 y entre 45 y 64.

Tramas. En cuanto a las tramas que ofrece la serie, se rechaza la hipótesis de nula de igualdad de media entre grupos de edad para dos cuestiones. La primera de ellas es "hay que estar muy atento para enterarse bien" ( $F=7.083, p<0.01)$. Los espectadores de 65 o más años claramente señalan la necesidad de estar muy atentos para enterarse bien de la serie. También consideran en mayor medida que el resto de televidentes que dentro de un mismo capítulo pasan cosas diferentes, aunque la asociación es más débil que para el ítem anterior $(\mathrm{F}=2.467, \mathrm{p}<0.10)$. No se han detectado diferencias significativas entre los diferentes grupos de edad en las opiniones acerca de la dificultad para seguir los episodios, la valoración de la complejidad de las historias, la existencia de muchas tramas diferentes en cada capítulo, la buena construcción de las historias o la capacidad que tiene la trama para enganchar al espectador.

Actores. Si se examina la asociación entre la edad y las creencias sobre los actores, el análisis de la varianza apunta a la inexistencia de diferencias estadísticamente significativas entre los cuatro grupos de edad considerados. Independientemente de la edad, los espectadores valoran de la misma forma que los actores son buenos, que interpretan bien su papel y que se ajustan muy bien a sus personajes.

Personajes. En cuanto a la relación entre edad y creencias sobre los personajes, para dos de las tres cuestiones consideradas no se rechaza la hipótesis nula de igualdad de medias entre los cuatro segmentos de edad. Concretamente, estos dos aspectos son la consideración sobre si los personajes son interesantes y sobre si están bien definidos. El único ítem sobre los personajes de Velvet para el que la asociación con la edad es significativa, aunque sea únicamente a un nivel de significación del 10\% ( $\mathrm{F}=2.375)$, es la credibilidad que transmiten. Sin embargo, la relación no es completamente lineal. Son los más mayores (65 o más años) a quienes más creíbles les resultan los personajes, seguidos por los de entre 45 y 64 años y los de 14 a 24, siendo los espectadores de entre 25 y 44 años quienes menor credibilidad otorgan a los personajes de Velvet.

Ambientación y vestuario. Para las creencias sobre la ambientación ( $\mathrm{F}=3.359, \mathrm{p}<0.05)$ y el vestuario de la serie $(\mathrm{F}=2.921$, $\mathrm{p}<0.05$ ) se detectan claras asociaciones con la edad. En ambos casos es el grupo de edad más veterano es el que otorga puntuaciones más altas a la serie. A continuación figurarían los dos grupos de edades intermedias, siendo los espectadores más jóvenes quienes peor valoran estos aspectos de Velvet.

Riqueza de recursos. En lo que se refiere a los recursos con los que ha contado la serie, no se hallan diferencias estadísticamente significativas entre grupos de edad para la creencia sobre la magnitud del presupuesto del que se ha dispuesto 
para el rodaje. Sin embargo, sí que se rechaza la hipótesis nula de igualdad de medias entre grupos de edad para la afirmación "en el rodaje no se ha escatimado en medios técnicos" (F02.914, p<0.05). En este caso se reproduce la ordenación mencionada para la ambientación y el vestuario: son los telespectadores de mayor edad quienes más creen que en el rodaje se ha contado con importantes medios técnicos, seguidos por la audiencia en edades intermedias y finalizando con los espectadores más jóvenes.

Contenidos molestos. En cuanto a las apreciaciones sobre la presencia de contenidos molestos en Velvet, no hay diferencias estadísticamente significativas entre los distintos grupos de edad. Ello es así para los tres aspectos considerados: en la serie pasan cosas desagradables, hay contenidos violentos y hay contenidos inmorales.

Originalidad. Tampoco se puede rechazar la hipótesis nula de igualdad de medias entre grupos de edad en los dos ítems relativos a la dimensión que recoge la originalidad de la serie. Todos los grupos de edad puntúan de forma muy similar el hecho de que la serie sea muy diferente a otras y que se trate de una serie muy original.

Variedad. En cuanto a las creencias sobre la variedad de la serie, sí que se detectan diferencias estadísticamente significativas en dos de los ítems considerados: "cada nuevo capítulo te sorprende" $(\mathrm{F}=2.552, \mathrm{p}<0.05)$ y "nunca sabes por donde va a ir la trama" ( $\mathrm{F}=2.577, \mathrm{p}<0.10)$. En ambos casos las puntuaciones son sustancialmente más altas en el caso de las personas de mayor edad, que consideran así la serie como más variada que el resto de grupos de edad. Sin embargo, esta relación no se detecta para el ítem "la serie no es nada repetitiva".

Calidad. Finalmente, para la valoración de la calidad de la serie se acepta la hipótesis nula de igualdad entre los diferentes grupos de edad. Aunque las puntuaciones de los ítems que miden la calidad son más elevadas en las personas de mayor edad, el análisis de la varianza indica que las diferencias no son estadísticamente significativas. Por lo tanto, puede afirmarse que los espectadores tienen una opinión similar sobre el nivel de calidad de la serie independientemente de su edad. Este resultado es llamativo en cuanto que para gran parte de las dimensiones estudiadas los espectadores de mayor edad mostraban unas creencias más positivas. 
Cuadro 3. Las creencias en función de la edad: resultados del análisis de la varianza

\begin{tabular}{|c|c|c|c|c|c|}
\hline & $14-24$ & $25-44$ & $45-64$ & 65 y más & F \\
\hline \multicolumn{6}{|l|}{ DIÁLOGOS } \\
\hline Las conversaciones de los protagonistas son muy interesantes & 4.94 & 5.13 & 5.23 & 5.99 & $2.681^{* *}$ \\
\hline Los diálogos son muy inteligentes & 4.68 & 4.91 & 4.69 & 5.60 & $2.713^{* *}$ \\
\hline Los diálogos están muy trabajados & 5 & 5.22 & 5.01 & 6.07 & $3.657^{* *}$ \\
\hline \multicolumn{6}{|l|}{ TRAMAS } \\
\hline Hay que estar muy atento para enterarse bien & 3.76 & 3.81 & 4.10 & 5.44 & $7.083^{* * *}$ \\
\hline Los episodios son difíciles de seguir & 2.89 & 2.83 & 3 & 2.97 & 0.119 \\
\hline Las historias son complicadas de entender & 2.71 & 2.63 & 3.12 & 2.81 & 0.837 \\
\hline Dentro de un mismo capítulo pasan cosas diferentes & 5.08 & 4.96 & 5.45 & 5.83 & $2.467^{*}$ \\
\hline Hay muchas tramas diferentes en cada capítulo & 4.44 & 4.68 & 4.96 & 5.20 & 1.517 \\
\hline Las historias están muy bien construidas & 6.67 & 6.49 & 6.08 & 6.59 & 0.916 \\
\hline La trama es tan buena que engancha rápidamente & 5.13 & 5.17 & 5.27 & 5.84 & 1.167 \\
\hline \multicolumn{6}{|l|}{ ACTORES } \\
\hline Los actores son muy buenos & 6.03 & 5.99 & 5.89 & 6.54 & 1.167 \\
\hline Los actores interpretan bien su papel & 6.40 & 6.13 & 6.16 & 6.91 & 1.983 \\
\hline Los actores se ajustan muy bien a sus personajes & 6.54 & 6.38 & 6.49 & 7.03 & 1.436 \\
\hline \multicolumn{6}{|l|}{ PERSONAJES } \\
\hline Los personajes me resultan muy creíbles & 6.14 & 5.76 & 6.26 & 6.69 & $2.375^{*}$ \\
\hline Los personajes son muy interesantes & 5.76 & 5.59 & 5.90 & 6.50 & 1.965 \\
\hline Los personajes están muy bien definidos & 6.32 & 6.25 & 6.41 & 6.80 & 0.977 \\
\hline \multicolumn{6}{|l|}{ AMIBENTACIÓN Y VESTUARIO } \\
\hline La ambientación está muy bien conseguida & 6.65 & 7.30 & 7.26 & 7.86 & $3.359^{* *}$ \\
\hline El vestuario es muy realista & 7.44 & 7.63 & 7.64 & 8.34 & $2.921^{* *}$ \\
\hline \multicolumn{6}{|l|}{ RIQUEZA DE RECURSOS } \\
\hline Se nota que la serie ha contado con un alto presupuesto & 6.52 & 7.01 & 6.79 & 7.37 & 1.873 \\
\hline En el rodaje no se ha escatimado en medios técnicos & 5.82 & 6.54 & 6.42 & 6.93 & $2.914^{* *}$ \\
\hline \multicolumn{6}{|l|}{ CONTENIDOS MOLESTOS } \\
\hline En la serie pasan cosas desagradables & 3.38 & 3.29 & 3.19 & 2.63 & 1.132 \\
\hline
\end{tabular}




\begin{tabular}{|c|c|c|c|c|c|}
\hline & $14-24$ & $25-44$ & $45-64$ & 65 y más & F \\
\hline Tiene contenidos violentos & 1.63 & 1.92 & 2.24 & 1.81 & 1.062 \\
\hline Tiene contenidos inmorales & 3.52 & 3.35 & 3.08 & 3.14 & 0.420 \\
\hline \multicolumn{6}{|l|}{ ORIGINALIDAD } \\
\hline Es muy diferente a otras series & 4.49 & 4.44 & 3.97 & 4.29 & 0.806 \\
\hline Es una serie muy original & 4.25 & 4.42 & 4.25 & 5.06 & 1.643 \\
\hline \multicolumn{6}{|l|}{ VARIEDAD } \\
\hline La serie no es nada repetitiva & 4.35 & 4.28 & 4.21 & 4.57 & 0.304 \\
\hline Cada nuevo capítulo te sorprende & 4.37 & 4.24 & 4.04 & 5.10 & $2.552^{* *}$ \\
\hline Nunca sabes por dónde va a ir la trama & 4.02 & 4.01 & 4.01 & 4.91 & $2.577^{*}$ \\
\hline \multicolumn{6}{|l|}{ CALIDAD } \\
\hline Está muy bien hecha & 6.11 & 6.39 & 6.68 & 6.93 & 1.874 \\
\hline Es una serie de calidad & 5.73 & 5.93 & 5.91 & 6.51 & 1.478 \\
\hline Es una serie excelente & 4.75 & 5 & 5.03 & 5.77 & 1.984 \\
\hline
\end{tabular}

Fuente: Elaboración propia

${ }^{*} \mathrm{p}<0.10,{ }^{* *} \mathrm{p}<0.05,{ }^{* * *} \mathrm{p}<0.01$

\subsection{La relación con el consumo de televisión}

En este apartado se analiza la relación existente entre las creencias sobre Velvet y el consumo de televisión. Para medir este consumo se emplean dos indicadores referidos a la cantidad de televisión que el telespectador ve. El primero de ellos es el promedio diario de horas que habitualmente ve la televisión de lunes a viernes. El segundo es el mismo indicador, sólo que aplicado al fin de semana. Para evaluar la asociación entre creencias y magnitud del consumo televisivo se han calculado los coeficientes de correlación de Pearson entre las diferentes variables (ver Cuadro 4). El coeficiente de correlación establece la relación entre dos variables cuantitativas. Se trata de comprobar si un alto consumo de televisión está relacionado con una mejor o peor valoración de cada una de las dimensiones. El rango del coeficiente de correlación es el intervalo que va desde - 1 hasta 1 , ambos incluidos. Un coeficiente de correlación de - 1 indica una correlación negativa perfecta, un valor de 0 la ausencia de correlación y un valor de 1 una correlación positiva perfecta. Se contrasta la hipótesis nula de que el coeficiente de correlación es cero, indicándose aquellos casos en los que ésta se rechaza a niveles de significación del $10 \%, 5 \%$ y $1 \%$. 
Diálogos. Los coeficientes de correlación entre los tres ítems utilizados para valorar esta cuestión y los dos indicadores de consumo de televisión son positivos, rechazándose la hipótesis nula de igualdad a cero. Esto implica que aquellos individuos más asiduos a la pequeña pantalla muestran una mayor propensión a considerar que los las conversaciones de los protagonistas de Velvet son muy interesantes y a creer que los diálogos son inteligentes y que están muy bien trabajados.

Tramas. En lo que se refiere a los resultados correspondientes a los siete aspectos de las tramas tenidos en cuenta, en esta ocasión detectamos que en una gran mayoría de los casos se obtiene un coeficiente de correlación positivo con el consumo de televisión y se rechaza la hipótesis nula de que sea igual a cero. Así, aquellos que ven la televisión durante un mayor número de horas tienden a creer que hay que estar muy atento a Velvet para enterarse bien, que dentro de un mismo capítulo pasan cosas diferentes, que hay muchas tramas diferentes en cada capítulo y que la trama es tan buena que engancha rápidamente. Por el contrario, no se aprecia relación con la percepción de que las historias son complicadas de entender. Además, hay dos cuestiones para las que se encuentra una correlación positiva y significativamente deistina de cero, pero débil ( $\mathrm{p}<0.10)$, con uno solo de los dos indicadores de consumo televisivo. Esto es lo que ocurre para la creencia de que los episodios son difíciles de seguir y el consumo de televisión entre semana y para las historias están muy bien construidas y el número de horas que se ve la televisión durante el fin de semana.

Actores. Mayor uniformidad se ha hallado en los resultados obtenidos en relación con las creencias sobre los actores que forman parte del reparto de Velvet. Para las tres cuestiones analizadas ("los actores son muy buenos", "los actores interpretan bien su papel”, y “los actores se ajustan muy bien a sus personajes”), se ha encontrado que aquellos consumidores más intensivos de televisión valoran mejor este aspecto de la serie, siendo los coeficientes de correlación distintos de cero a un nivel de significación del $1 \%$.

Personajes. Los resultados obtenidos para la valoración de los personajes van en la misma dirección de los conseguidos para los actores. Esto significa que el número de horas de televisión visionadas diariamente, tanto de lunes a viernes como en fin de semana, está relacionado positivamente con una opinión más favorable sobre la credibilidad, el interés y la buena definición de los personajes de Velvet. Como en el caso anterior, se rechaza la hipótesis nula de coeficientes iguales a cero con una significación estadística del $1 \%$.

Ambientación y vestuario. Las correlaciones obtenidas entre los dos ítems referentes a la ambientación y el vestuario y las dos medidas de consumo televisivo apuntan con claridad a que aquellas personas que ven diariamente un mayor número de horas la televisión tienden a tener a creer que la ambientación de Velvet está muy bien conseguida y que el vestuario utilizado por los personajes es muy realista. En todos los casos, se rechaza la hipótesis nula de que el coeficiente de correlación sea igual a cero con una significación estadística del 1\%. 
Riqueza de recursos. En lo que se refiere a las creencias sobre la riqueza de medios de los que dispone la serie para su elaboración, a semejanza de lo hallado para otras dimensiones, se observa que el mayor consumo televisivo, independientemente del dia de la semana en que se realice, está asociado significativamente a considerar que Velvet ha contado con un alto presupuesto y a pensar que en el rodaje no se ha escatimado en medios técnicos. No obstante, hay que subrayar que en esta ocasión los valores de las correlaciones son menores que en casos anteriores, lo que redunda en algunas de las significaciones estadísticas con las que se rechaza la hipótesis nula.

Contenidos molestos. A diferencia de lo sucedido para las dimensiones estudiadas hasta ahora, no existen relaciones positivas entre el consumo televisivo y la percepción de que en Velvet hay contenidos molestos. En la mayoría de los casos se acepta la hipótesis nula de que el número de horas que se ve la televisión no está correlacionado con las creencias del espectador en relación con esta cuestión. La única relación estadísticamente significativa encontrada, de signo negativo, es entre el número de horas diarias que se ve la televisión entre semana y la percepción de que en Velvet se emiten contenidos inmorales. Esto es, aquellos espectadores que dedican menos tiempo de lunes a viernes a ver la televisión creen en mayor medida que Velvet posee contenidos inmorales.

Originalidad. La asociación de la percepción de la originalidad de Velvet con el consumo televisivo no queda perfectamente aclarada a través de nuestros análisis. Si bien tres de las cuatro correlaciones son positivas y significativamente diferentes de cero, hay una que no lo es. Concretamente, la asociación entre la creencia de que Velvet es muy diferente a otras series y el número de horas que se ve la televisión de lunes a viernes es cercana a cero, no pudiéndose rechazar la hipótesis nula.

Variedad. Las correlaciones entre los tres ítems con los que se mide las creencias sobre la variedad de Velvet y las dos medidas de consumo de televisión son siempre positivas y significativamente distintas de cero. Por lo tanto, se puede aceptar la hipótesis alternativa de que los más asiduos a ver la televisión creen en mayor medida que los que no lo hacen que Velvet es una serie nada repetitiva, que cada nuevo capítulo de ella te sorprende y que nunca se sabe por dónde va a ir la trama.

Calidad. Finalmente, para los tres ítems que miden las creencias de los telespectadores sobre la calidad de Velvet, se encuentran correlaciones positivas con el número de horas de consumo televisivo, tanto entre semana como en fin de semana. Los resultados indican que no se acepta la hipótesis nula de inexistencia de correlación. Esto viene a confirmar lo detectado para el resto de dimensiones: aquellos espectadores que consumen más televisión tienden a tener una visión más favorable de Velvet. 
Cuadro 4. Creencias y nivel de consumo televisivo: análisis de correlaciones

\begin{tabular}{|c|c|c|}
\hline & Entre semana & Fin de semana \\
\hline \multicolumn{3}{|l|}{ DIÁLOGOS } \\
\hline Las conversaciones de los protagonistas son muy interesantes & $0.205^{* * *}$ & $0.205^{* * *}$ \\
\hline Los diálogos son muy inteligentes & $0.213^{* * *}$ & $0.229^{* * *}$ \\
\hline Los diálogos están muy trabajados & $0.235^{* * *}$ & $0.261^{* * *}$ \\
\hline \multicolumn{3}{|l|}{ TRAMAS } \\
\hline Hay que estar muy atento para enterarse bien & $0.227^{* * *}$ & $0.168^{* * *}$ \\
\hline Los episodios son difíciles de seguir & $0.086^{*}$ & 0.055 \\
\hline Las historias son complicadas de entender & 0.057 & -0.021 \\
\hline Dentro de un mismo capítulo pasan cosas diferentes & $0.150^{* * *}$ & $0.203^{* * *}$ \\
\hline Hay muchas tramas diferentes en cada capítulo & $0.118^{* *}$ & $0.124^{* *}$ \\
\hline Las historias están muy bien construidas & 0.009 & $0.095^{*}$ \\
\hline La trama es tan buena que engancha rápidamente & $0.173^{* * *}$ & $0.193^{* * *}$ \\
\hline \multicolumn{3}{|l|}{ ACTORES } \\
\hline Los actores son muy buenos & $0.199 * * *$ & $0.238^{* * *}$ \\
\hline Los actores interpretan bien su papel & $0.201^{* * *}$ & $0.235^{* * *}$ \\
\hline Los actores se ajustan muy bien a sus personajes & $0.206^{* * *}$ & $0.215^{* * *}$ \\
\hline \multicolumn{3}{|l|}{ PERSONAJES } \\
\hline Los personajes me resultan muy creíbles & $0.253^{* * *}$ & $0.251^{* * *}$ \\
\hline Los personajes son muy interesantes & $0.251^{* * *}$ & $0.293^{* * *}$ \\
\hline Los personajes están muy bien definidos & $0.168^{* * *}$ & $0.225^{* * *}$ \\
\hline \multicolumn{3}{|l|}{ AMBIENTACIÓN Y VESTUARIO } \\
\hline La ambientación está muy bien conseguida & $0.155^{* * *}$ & $0.161^{* * *}$ \\
\hline El vestuario es muy realista & $0.156^{* * *}$ & $0.166^{* * *}$ \\
\hline \multicolumn{3}{|l|}{ RIQUEZA DE RECURSOS } \\
\hline Se nota que la serie ha contado con un alto presupuesto & $0.142^{* * *}$ & $0.090^{*}$ \\
\hline En el rodaje no se ha escatimado en medios técnicos & $0.125^{* *}$ & $0.103^{* *}$ \\
\hline \multicolumn{3}{|l|}{ CONTENIDOS MOLESTOS } \\
\hline En la serie pasan cosas desagradables & -0.020 & 0.018 \\
\hline
\end{tabular}




\begin{tabular}{|l|c|c|}
\hline & Entre semana & Fin de semana \\
\hline Tiene contenidos violentos & 0.023 & -0.016 \\
\hline Tiene contenidos inmorales & $-0.119^{* *}$ & -0.049 \\
\hline ORIGINALIDAD & 0.045 & $0.119^{* *}$ \\
\hline Es muy diferente a otras series & $0.130^{* *}$ & $0.231^{* * *}$ \\
\hline Es una serie muy original & \multicolumn{1}{|l|}{} \\
\hline VARIEDAD & $0.119^{* *}$ & $0.136^{* * *}$ \\
\hline La serie no es nada repetitiva & $0.177^{* * *}$ & $0.193^{* * *}$ \\
\hline Cada nuevo capítulo te sorprende & $0.155^{* * *}$ & $0.154^{* * *}$ \\
\hline Nunca sabes por dónde va a ir la trama & & \\
\hline CALIDAD & $0.193^{* * *}$ & $0.221^{* * *}$ \\
\hline Está muy bien hecha & $0.191^{* * *}$ & $0.238^{* * *}$ \\
\hline Es una serie de calidad & $0.180^{* * *}$ & $0.246^{* * *}$ \\
\hline Es una serie excelente & &
\end{tabular}

Fuente: Elaboración propia

${ }^{*} \mathrm{p}<0.10,{ }^{* *} \mathrm{p}<0.05,{ }^{* * *} \mathrm{p}<0.01$

\subsection{La relación con las preferencias por géneros de series de ficción}

A continuación se va a estudiar la relación entre las creencias de los espectadores sobre Velvet y sus preferencias en relación con diferentes géneros de ficción televisiva. Concretamente los géneros tenidos en cuenta son los cinco siguientes: drama, comedia, policiaca, aventura/acción y suspense. El entrevistado tuvo que evaluar su preferencia por cada uno de estos géneros en una escala de cero a diez, donde cero indica que el género no le gusta nada y diez que muchísimo. De la misma forma que para el consumo televisivo, la asociación con las creencias sobre Velvet se realiza a través del análisis de los correspondientes coeficientes de correlación y el contraste de hipótesis de igualdad a cero (ver Cuadro 5).

Diálogos. Los tres ítems utilizados para evaluar las percepciones sobre los diálogos en Velvet muestran patrones bastante similares. De esta manera, se observa que la consideración positiva de ellos por el telespectador está asociada positivamente a la preferencia por el drama y la comedia. No se acepta, por tanto, la hipótesis nula de ausencia de correlación. Asimismo, no hay asociación estadísticamente significativa con el gusto por las series de acción o de suspense. Sin embargo, se encuentra, aunque débilmente $(\mathrm{p}<0.10)$, que aquellos individuos a los que les gustan las series policiacas, consideran en menor medida que las conversaciones de los protagonistas de Velvet son muy interesantes o que los diálogos son muy inteligentes. 
Tramas. En cuanto a las tramas, para tres de los ítems contemplados dentro de esta dimensión no se encuentran asociaciones estadísticamente significativas con las preferencias por género de ficción. Se trata de "los episodios son difíciles de seguir", "las historias son complicadas de entender", y “las historias están muy bien construidas". Sin embargo, para los dos ítems directamente relacionados con que suceden muchas cosas en cada capítulo se detecta $(\mathrm{p}<0.05)$ que esta creencia está vinculada notablemente con el gusto por las series dramáticas. En el caso de la percepción de que hay que estar muy atento para enterarse bien de lo que ocurre en Velvet, se detecta que estás significativa y positivamente asociada a la preferencia por los dramas y significativa y negativamente a la preferencia por las series policiacas, aunque en ambos casos la intensidad de la asociación es débil $(\mathrm{p}<0.10)$. Finalmente, la opinión respecto a la calidad de la trama de Velvet y su capacidad para enganchar, los aficionados a los dramas tienden de una forma estadísticamente significativa a creer que es así, mientras que los que prefieren las series de policiacas y de acción creen justamente lo contrario.

Actores. El patrón de correlaciones hallado para los tres aspectos considerados referidos a los actores que participan en Velvet es prácticamente idéntico. Los resultados indican que aquellos telespectadores a los que les gustan las series dramáticas y las comedias tienden a valorar mejor a los actores de Velvet, señalando que son muy buenos, que interpretan bien su papel y que se ajustan muy bien a sus personajes. El nivel de significación con el que se rechaza la hipótesis nula de ausencia de asociación en estos casos es el $5 \%$.

Personajes. Los resultados obtenidos en relación con las creencias sobre los personajes reproducen con bastante fidelidad los hallados para las creencias sobre los actores de Velvet. En consecuencia, se han encontrado correlaciones positivas y estadísticamente significativas entre estas creencias y las preferencias de los espectadores por el drama y la comedia, sin que se haya detectado asociación estadísticamente significativa en una u otra dirección con el gusto por las series policiacas, las de aventura y acción, y las de suspense.

Ambientación y vestuario. Los resultados alcanzados en relación con las creencias acerca de la ambientación y el vestuario de Velvet se separan en varios aspectos de los que hemos venido comentando para otras dimensiones. Así, la opinión positiva sobre la ambientación en Velvet está correlacionada positivamente con la preferencia por el drama ( $<<0.05)$, como sucedía en casos anteriores, pero también con el gusto por la comedia $(\mathrm{p}<0.05)$ y por las series de suspense $(\mathrm{p}<0.05)$. En cuanto al realismo del vestuario, su consideración es especialmente positiva por parte de aquellos televidentes que muestran preferencia por el drama $(\mathrm{p}<0.10)$ y de aquellos a los que no les agradan las series de aventura y de acción $(\mathrm{p}<0.05)$.

Riqueza de recursos. También las creencias respecto a la riqueza de medios con los que ha contado la serie para su rodaje se separa ligeramente de lo que viene siendo la pauta general del resto de creencias analizadas hasta ahora en su relación con las preferencias de género de ficción televisiva. Los resultados difieren para los dos ítems tenidos en cuenta para analizar esta cuestión. De esta manera, el grado de acuerdo con la afirmación "se nota que la serie ha contado con un alto presupuesto" es significativamente mayor entre quienes indican que les gustan las series policiacas $(p<0.05)$ y las de sus- 
pense $(\mathrm{p}<0.10)$. Por su parte, el acuerdo con la afirmación "en el rodaje no se ha escatimado en medios técnicos" es más habitual entre los aficionados a los dramas, rechazándose la hipótesis nula de ausencia de correlación con un nivel de significación del $10 \%$.

Contenidos molestos. Se han encontrado diferencias importantes entre los tres ítems que se emplean en este trabajo para capturar esta cuestión. Por ejemplo, los individuos que prefieren las series de aventura y acción consideran en mayor medida que en Velvet pasan cosas desagradables $(\mathrm{p}<0.10)$, pero no difieren del resto de espectadores en relación con las otras dos cuestiones. Por su lado, los que muestran preferencia por el drama tienden a opinar con una intensidad significativamente distinta de cero desde el punto de vista estadístico ( $\mathrm{p}<0.05)$ que Velvet contiene elementos de violencia. En lo que respecta a la opinión sobre la presencia de contenidos inmorales, no se puede rechazar la hipótesis de ausencia de correlación con la preferencia por un género de ficción u otro.

Originalidad. Los dos ítems que miden la percepción de los entrevistados respecto a la originalidad de Velvet presentan un patrón común en su correlación con las preferencias por los diferentes géneros de ficción. Concretamente, aquellos espectadores a quienes les gustan los dramas son más propensos a opinar que Velvet es muy diferente a otras series y que se trata de una serie muy original $(\mathrm{p}<0.01)$. No se ha podido aceptar la hipótesis alternativa de existencia de asociación con las preferencias por el resto de géneros de ficción.

Variedad. El análisis de correlaciones para las creencias sobre la variedad de Velvet y la preferencia por géneros de ficción televisiva ofrece los siguientes resultados. Para los tres ítems considerados en esta cuestión ("la serie no es nada repetitiva", "cada nuevo capítulo te sorprende", y "nunca sabes por donde va a ir la trama") se obtiene que las valoraciones de los telespectadores son mayores cuando éstos son aficionados las series dramáticas. Además, los dos primeros ítems obtienen puntuaciones más elevadas por parte de aquellos espectadores que indican que les gustan las comedias. Para los tres géneros restantes, se acepta la hipótesis nula de ausencia de asociación con este apartado de las creencias.

Calidad. Para terminar, en el Cuadro 5 se examina la asociación entre la opinión sobre la calidad de Velvet y la preferencia por géneros de ficción televisiva. La opinión de que la serie está muy bien hecha no se correlaciona significativamente desde el punto de vista estadístico con el gusto por ninguno de los cinco géneros tomados en consideración. Para la opinión de que Velvet es una serie de calidad se halla que esta creencia se manifiesta especialmente entre los que dicen que les gustan las series dramáticas $(\mathrm{p}<0.01)$. En cuanto a la consideración de Velvet como una serie excelente, se repite este resultado ( $<<0.01$ ), pero a su vez, se observa que aquellos espectadores a los que les gustan las series de aventura y de acción tienden a mostrase más contrarios a esta afirmación ( $\mathrm{p}<0.05)$. 
Cuadro 5. Creencias y preferencias por género de serie de ficción: análisis de correlaciones

\begin{tabular}{|c|c|c|c|c|c|}
\hline & Drama & Comedia & Policíaca & $\begin{array}{l}\text { Aventura } \\
\text { acción }\end{array}$ & Suspense \\
\hline \multicolumn{6}{|l|}{ DIÁLOGOS } \\
\hline Las conversaciones de los protagonistas son muy interesantes & $0.228^{* * *}$ & $0.139 * * *$ & $-0.093^{*}$ & -0.084 & -0.003 \\
\hline Los diálogos son muy inteligentes & $0.146^{* * *}$ & $0.136^{* * *}$ & $-0.088^{*}$ & -0.051 & -0.005 \\
\hline Los diálogos están muy trabajados & $0.174^{* * *}$ & $0.169^{* * *}$ & -0.028 & -0.009 & 0.032 \\
\hline \multicolumn{6}{|l|}{ TRAMAS } \\
\hline Hay que estar muy atento para enterarse bien & $0.113^{*}$ & -0.009 & $-0.085^{*}$ & -0.036 & 0.047 \\
\hline Los episodios son difíciles de seguir & 0.047 & 0.009 & 0.044 & -0.017 & -0.006 \\
\hline Las historias son complicadas de entender & 0.039 & 0.025 & -0.017 & -0.051 & -0.054 \\
\hline Dentro de un mismo capítulo pasan cosas diferentes & $0.128^{* *}$ & -0.019 & -0.012 & -0.044 & -0.011 \\
\hline Hay muchas tramas diferentes en cada capítulo & $0.120^{* *}$ & 0.070 & 0.008 & -0.019 & 0.054 \\
\hline Las historias están muy bien construidas & -0.029 & 0.026 & 0.016 & 0.001 & 0.022 \\
\hline La trama es tan buena que engancha rápidamente & $0.146^{* * *}$ & 0.009 & $-0.104^{* *}$ & $-0.088^{*}$ & -0.014 \\
\hline \multicolumn{6}{|l|}{ ACTORES } \\
\hline Los actores son muy buenos & $0.104^{* *}$ & $0.116^{* *}$ & -0.011 & -0.018 & 0.050 \\
\hline Los actores interpretan bien su papel & $0.119^{* *}$ & $0.114^{* *}$ & 0.009 & -0.043 & -0.007 \\
\hline Los actores se ajustan muy bien a sus personajes & $0.115^{* *}$ & $0.125^{* *}$ & -0.009 & -0.047 & -0.003 \\
\hline \multicolumn{6}{|l|}{ PERSONAJES } \\
\hline Los personajes me resultan muy creíbles & $0.108^{* *}$ & $0.130^{* *}$ & 0.009 & 0.058 & -0.003 \\
\hline Los personajes son muy interesantes & $0.167^{* * *}$ & $0.161^{* * *}$ & -0.056 & -0.023 & -0.011 \\
\hline Los personajes están muy bien definidos & $0.154^{* * *}$ & $0.159^{* * *}$ & -0.003 & -0.023 & -0.035 \\
\hline \multicolumn{6}{|l|}{ AMBIENTACIÓN Y VESTUARIO } \\
\hline La ambientación está muy bien conseguida & $0.124^{* *}$ & $0.119^{* *}$ & 0.009 & -0.035 & $0.159^{* * *}$ \\
\hline El vestuario es muy realista & $0.091^{*}$ & 0.058 & 0.007 & $-0.103^{* *}$ & 0.051 \\
\hline \multicolumn{6}{|l|}{ RIQUEZA DE RECURSOS } \\
\hline Se nota que la serie ha contado con un alto presupuesto & 0.036 & 0.025 & $0.122^{* *}$ & 0.004 & $0.092^{*}$ \\
\hline En el rodaje no se ha escatimado en medios técnicos & $0.089^{*}$ & 0.007 & 0.067 & -0.019 & 0.079 \\
\hline \multicolumn{6}{|l|}{ CONTENIDOS MOLESTOS } \\
\hline En la serie pasan cosas desagradables & 0.043 & -0.070 & -0.025 & $0.087^{*}$ & 0.007 \\
\hline
\end{tabular}




\begin{tabular}{|c|c|c|c|c|c|}
\hline & Drama & Comedia & Policíaca & $\begin{array}{l}\text { Aventura } \\
\text { acción }\end{array}$ & Suspense \\
\hline Tiene contenidos violentos & $0.129^{* *}$ & -0.006 & -0.001 & 0.058 & 0.070 \\
\hline Tiene contenidos inmorales & 0.048 & 0.045 & 0.007 & 0.013 & -0.010 \\
\hline \multicolumn{6}{|l|}{ ORIGINALIDAD } \\
\hline Es muy diferente a otras series & $0.142^{* * *}$ & 0.067 & -0.077 & -0.050 & -0.044 \\
\hline Es una serie muy original & $0.142^{* * *}$ & 0.003 & -0.071 & -0.083 & 0.018 \\
\hline \multicolumn{6}{|l|}{ VARIEDAD } \\
\hline La serie no es nada repetitiva & $0.150^{* * *}$ & $0.093^{*}$ & -0.046 & -0.017 & -0.028 \\
\hline Cada nuevo capítulo te sorprende & $0.140^{* * *}$ & $0.133^{* * *}$ & -0.024 & -0.057 & 0.046 \\
\hline Nunca sabes por dónde va a ir la trama & $0.099^{* *}$ & 0.023 & 0.029 & -0.050 & 0.047 \\
\hline \multicolumn{6}{|l|}{ CALIDAD } \\
\hline Está muy bien hecha & 0.069 & 0.037 & -0.074 & -0.077 & -0.006 \\
\hline Es una serie de calidad & $0.145^{* * *}$ & 0.050 & -0.051 & -0.064 & -0.018 \\
\hline Es una serie excelente & $0.151^{* * *}$ & 0.069 & -0.069 & $-0.116^{* *}$ & -0.025 \\
\hline
\end{tabular}

Fuente: Elaboración propia

${ }^{*} \mathrm{p}<0.10,{ }^{* *} \mathrm{p}<0.05,{ }^{* * *} \mathrm{p}<0.01$

\section{Conclusiones}

El objetivo de este trabajo ha sido ofrecer un modelo teórico y una herramienta que permita analizar de una forma pormenorizada las creencias de los telespectadores respecto a las series de ficción televisiva. Con este fin se ha realizado una aplicación a Velvet, emitida por vez primera en Antena 3 en la temporada 2013. Más concretamente, este trabajo ha permitido indagar en cuáles son las creencias que los espectadores tienen sobre la serie mediante la valoración de hasta diez aspectos de la misma (diálogos, tramas, actores, personajes, ambientación y vestuario, riqueza de recursos, contenidos inmorales, originalidad, variedad y calidad). Este trabajo ha permitido realizar un análisis sistematizado de las opiniones de los telespectadores respecto a la serie más allá de las cifras de audiencia. Aunque éstas son muy relevantes para acotar y medir el grado de aceptación de la serie, cuentan con la limitación de ofrecer escasa información sobre los factores que explican su mayor o menor éxito.

Como primera conclusión diremos que los aspectos de Velvet mejor valorados por los espectadores son la ambientación y vestuario y la riqueza de recursos con que cuenta la serie. Seguidos en puntuación se encuentran los actores y los per- 
sonajes, que se consideran como bien construidos. Los aspectos peor valorados son la variedad y la originalidad de la serie. Los contenidos de la serie no se consideran molestos ni desagradables. Todo ello hace que la evaluación final de la calidad de la serie sea de casi seis puntos sobre diez $(5,9)$.

Estos resultados ofrecen un cuadro bastante claro sobre cuáles son los puntos fuertes y débiles de la serie de acuerdo con la opinión de los telespectadores y, en consecuencia, ofrecen pautas nítidas dirigidas a mejorar la aceptación de la serie por los telespectadores.

Profundizando en la influencia que pudieran tener en la valoración de las dimensiones consideradas las variables sociodemográficas sexo y edad, se ha detectado que ambas están relacionadas con las creencias sobre la serie. En cuanto a los aspectos mejor valorados de la serie, se ha hallado que las mujeres valoran mucho mejor que los hombres la ambientación y el vestuario, pero no hay diferencias entre ambos en cuanto a la percepción sobre la riqueza de recursos de la serie. También las mujeres consideran significativamente mejor a los actores y a los personajes de la serie. También los diálogos les resultan más atractivos a las mujeres que a los hombres. En el resto de dimensiones no se han encontrado diferencias entre ambos sexos.

Analizando las diferencias por edades, se ha detectado que la ambientación, el vestuario y la riqueza de recursos son mucho mejor valorados por las personas de más edad, ocurriendo lo mismo con los diálogos y la variedad. No se observan diferencias por edades en la consideración de los personajes y actores, así como tampoco en las tramas, aunque las personas de más edad sí que manifiestan que deben estar muy atentos para enterarse bien de las mismas.

Así pues, una segunda conclusión del trabajo sería que hombres y mujeres valoran de forma diferente la mayoría de las dimensiones de la serie, dando las mujeres puntuaciones más altas. La calidad de la serie es para las mujeres, significativamente más alta que para los hombres. Esto indica que se trata de una serie que cuenta claramente con una mayor aceptación entre el público femenino. A pesar de ello, la ordenación de las dimensiones consideradas no difiere entre hombres y mujeres. La tercera conclusión a la que se llega es que las diferencias entre espectadores de diferentes edades son de importancia únicamente en cuatro de las dimensiones analizadas: ambientación y vestuario, riqueza de recursos, diálogos y variedad de la serie. Sin embargo, la percepción de calidad de la serie no se está relacionada con la edad del televidente.

A partir de la definición del público objetivo de la serie en términos de sexo y edad, que no tiene por qué coincidir con la realidad de la audiencia, y de los resultados aquí obtenidos, los productores disponen de información sobre aquellos puntos susceptibles de mejora de cara a atraer al perfil de espectador deseado.

Otro de los aspectos analizados ha sido el perfil de consumo de televisión del espectador. Se observa que las personas que consumen más televisión, tanto entre semana como en fin de semana, valoran mucho mejor todas las dimensiones de la 
serie. De esta forma, no encuentran molestos los contenidos de la serie y consideran a ésta más original, más variada y de más calidad que aquellos espectadores que ven menos televisión. Los que ven más televisión entre semana no consideran que la serie sea muy diferente a otras.

Por último, el estudio de las diferencias de opiniones sobre la serie en función de las preferencias de géneros de ficción del espectador también aporta conclusiones interesantes. En general los aficionados al drama y a la comedia son lo que mejor valoran los distintos aspectos de la serie en contraposición a los aficionados a los géneros policiaco, de aventura y de suspense. Para los que muestran preferencia por drama y comedia, los actores y personajes de Velvet, así como sus diálogos son mejores que para el resto. Lo mismo ocurre con la ambientación y vestuario y la variedad de la serie, aunque sólo la valoran como más original aquellos a los que les gusta el drama. Son estos últimos también los que consideran la serie como de mayor calidad.

Por tanto, la cuarta y última conclusión del estudio sería que los heavy consumers de televisión valoran mucho mejor la serie que aquellos que no la ven tanto y que son los aficionados a los géneros de drama y comedia los que valoran mejor muchos de los aspectos considerados en Velvet.

Los resultados de este estudio permiten ofrecer algunas conclusiones relevantes que contribuyen al debate alrededor del concepto de calidad de los productos audiovisuales desde el punto de vista del consumidor. De esta forma, se muestra que el concepto de calidad percibida de los programas televisivos es multidimensional. Aunque la valoración global de la calidad de un producto audiovisual proporciona información útil que permite medir la aceptación y el éxito entre la audiencia, nuestros resultados indican que es preciso un análisis más pormenorizado de lo que hay detrás de esta percepción. Hemos comprobado para el caso de Velvet que en la valoración global de la calidad de esta serie, el público tiene en cuenta distintos aspectos, de forma que el resultado final se sitúa en una posición intermedia entre los aspectos mejor valorados y los no tan bien considerados. Asimismo, nuestros resultados apuntan a que las creencias de un espectador sobre un determinado programa contienen elementos claramente subjetivos vinculados a sus características sociodemográficas y a sus patrones de consumo y gustos televisivos. Ello sugiere que desde el punto de vista del telespectador, la calidad percibida implica cierto componente de satisfacción de los gustos personales, más allá de los atributos técnicos objetivos. No obstante, nuestros resultados también apuntan a la existencia de coincidencias en la ordenación de las creencias. Así, en nuestro caso la ambientación y el vestuario de Velvet tienen mejor consideración por parte de la audiencia que el resto de aspectos abordados. Lógicamente esto debería llevar a pensar que objetivamente nos encontramos ante un parámetro en que Velvet objetivamente destaca. 


\section{Referencias bibliográficas}

Cohen, J. (2001): "Defining identification: a theoretical look at the identification of audiences with media characters", Mass Communication and Society, vol. 4 (3), pp. 245-264.

De Wied, M., Zillmann, D. y Ordman, V. (1994): “The rol of empathic distress in the enjoyement of cinematic tragedy", Poetics, vol. 23, pp. 91-106.

Fishbein, M. y Ajzen, I. (1975): Attitude, intention and behavior: An introduction to theory and research. Reading, Massachusett: Addison-Wesley.

García de Castro, M. (2002): La ficción televisiva popular. Una evolución de las series de televisión españolas. Barcelona, Gedisa.

García de Castro, M. (2002): “Los movimientos de renovación en las series televisivas españolas”, Comunicar, n. 30, pp.147153.

Igartua, J. J. y Múñiz, C. (2008): “Identificación con los personajes y disfrute ante largometrajes de ficción. Una investigación empírica”. Comunicación y Sociedad, vol. 21 (1), pp. 25-52.

Igartua, J. J. y Páez, D. (1997): "Art of remembering traumatic collective events; the case of Spanish Civil War", en Pennebaker, J., Páez, D. y Rimé, B. (eds.): Collective memory of political event. Social psychological perspectives. Lawrence Erlbaum Associates, pp. 79-101.

(1997): “El cine sobre la Guerra Civil Española. Una investigación sobre su impacto en creencias y actitudes”, Boletín de Psicología, vol. 57, pp. 7-39.

- $\quad$ (1998): "Fiabilidad y validez de una escala de empatía e identificación con los personajes", Psicothema, vol. 10 (2), pp. 423-436.

Kantar Media (2013): Anuario de audiencia de televisión 2013.

Larsen, S. F., Laszlo, J. (1990): “Cultural-historical knowledge and personal experience in appreciation of literature”, European Journal of Social Psychology, vol. 20, pp. 425-440.

Oliver, M. B. (1993): “Exploring the paradox of the enjoyment of sad films”, Human Communication Research, vol. 19 (3), pp. 315-342.

Oliver, M. B. (2003): “Mood management and selective exposure”, en Bryant, J., Roskos-Ewolsen, D. y Cantor, J. (eds.): Communication and emotion. Essays in honor of Dolf Zillman. Lawrence Erlbaum Associates, pp. 85-106.

Packer, M. (1989): "Dissolving the paradox of tragedy", The Journal of Aesthetics and Art Criticism, vol. 47 (3), pp. 211-219.

Petty, R. E., Cacioppo, J. T. (1981): Attitudes and persuasion: Classic and contemporary approaches. Dubuque, Iowa: Wm. C. Brown. 
Vorderer, P., Klimmt, C. y Ritterfeld, U. (2004): “Enjoyment, at the heart of media enterteinment”, Communication Theory, vol. 14 (4), pp. 388-408.

\section{Otros recursos:}

Antena 3 TV (2014): “'Velvet' finaliza su primera temporada líder con más de 4,2 millones de media (21,8\%)”. Disponible en: http://www.antena3.com/objetivotv/analisis/velvet-finaliza-primera-temporada-lider-mas-millones-media-218_ 2014052700035.html. [Consultado el 15/06/2014].

Campos, R. (2013): “Cada capítulo de Galerías Velvet cuesta unos 500.000 euros”. Disponible en: http://www.cadenaser.com/cultura/articulo/capitulo-galerias-velvet-cuesta-500000-euros/csrcsrpor/20131014 csrcsrcul_1/Tes. [Consultado el 10/10/2014]. 